\title{
SÍNDROME DE BURNOUT: SOLICITUD DE RECONOCIMIENTO COMO ENFERMEDAD PROFESIONAL EN EL CUERPO DE FUNCIONARIOS DE LA UNIÓN EUROPEA. RESPETO DEL DERECHO A SER OÍDO
}

\section{BURNOUT SYNDROME: APPLICATION FOR RECOGNITION AS AN OCCUPATIONAL DISEASE IN THE BODY OF OFFICIALS OF THE EUROPEAN UNION. RESPECT FOR THE RIGHT TO BE HEARD}

\section{Juliana Da Silva Martínez}

DOI: https://doi.org/10.37767/2591-3476(2021)10

\section{Comentario a}

UE/Comisión Europea, 23 de septiembre de 2020, asunto T-338/19

Tribunal General de la Unión Europea

\section{Disponible en}

https://bit.ly/3zr20qz

\section{RESUMEN:}

Este artículo analiza la sentencia del Tribunal General de la Unión Europea, de 23 de septiembre de 2020, en un asunto entre la Comisión Europea y una antigua empleada de la Agencia Europea de Reconstrucción, mediante el cual se discute la admisibilidad de la solicitud del reconocimiento de la enfermedad del síndrome de burnout como enfermedad profesional, instada con arreglo al art. 73 del Estatuto de los Funcionarios de la Unión Europea. 


\begin{abstract}
This article analyzes the judgment of the General Court of the European Union, of September 23, 2020, in a matter between the European Commission and a former employee of the European Agency for Reconstruction, which discusses if it is admissible the application for recognition of the disease of burnout syndrome as an occupational disease, in accordance with art. 73 of the Staff Regulations of Officials.
\end{abstract}

PALABRAS CLAVE: Burnout; Carta; enfermedad; Europa; funcionarios; derechos.

KEY WORDS: Burnout; Charter; disease; Europe; officials; rights.

\title{
I. Introducción
}

Mediante este comentario se analiza la sentencia del Tribunal General de la Unión Europea, de 23 de septiembre de 2020. En base al art. 270 TFUE, la demandante presenta un recurso ante el TJUE contra la decisión de la Oficina de Gestión y Liquidación de los Derechos Individuales de la Comisión Europea, de inadmitir la solicitud de reconocimiento de una enfermedad profesional por extemporaneidad. El Tribunal General mediante esta sentencia analiza si efectivamente hubo vulneración del derecho a ser oído, y por consiguiente si se ha generado indefensión para que dicha decisión pueda ser anulada. La enfermedad objeto de la solicitud de reconocimiento es el síndrome de desgaste profesional, mejor conocida por su término en inglés "burnout".

\section{Antecedentes de hecho}

A causa de los servicios prestados en la Agencia Europea de Reconstrucción a lo largo de ocho años de trabajo, concretamente desde el año 2000 al año 2008, la demandante alega una serie de patologías, en su mayoría de carácter psicológico, calificadas de desgaste profesional o burnout.

En el art. 24 del Estatuto de Funcionarios de la Unión Europea, que era aplicable a la demandante, se garantiza asistencia al funcionario europeo "mediante la persecución contra los autores de amenazas, ultrajes, injurias, difamaciones o atentados contra la persona y los bienes". Este artículo también garantiza la reparación solidaria por parte de la UE de los daños sufridos en caso de que el autor no los pague.

Sobre la base de este artículo, la demandante en el año 2013 presenta una solicitud de asistencia frente a la situación de acoso psicológico sufría en el ámbito laboral, con el consiguiente deterioro de su salud, junto a la solicitud de una indemnización por los daños sufridos. No obstante, mediante una decisión del 4 de octubre de 2016 la autoridad facultada para celebrar los contratos de trabajo (AFCC) desestimó dichas solicitudes, en base a que no quedaba totalmente acreditado mediante los certificados médicos que las patologías psicológicas sufridas fueron causadas directamente por el acoso psicológico en el ambiente de trabajo. Tras sendas reclamaciones y recursos presentados por la demandante y desestimados por la autoridad mencionada, ella presenta un recurso ante el Tribunal de Justicia de la Unión Europea con el objetivo de anular la decisión desestimatoria del 4 de octubre de 2016, entre otras decisiones; no obstante logran las partes un acuerdo, siendo así el procedimiento archivado. 
Posteriormente, el 3 de mayo del año 2017 la demandante insta a la Oficina de Gestión y Liquidación de los Derechos Individuales de la Comisión Europea una solicitud de reconocimiento del origen profesional de su enfermedad, en base el art. 73 del Estatuto de Funcionarios de la Unión Europea. Dicho reconocimiento sería realizado con arreglo al art. 16 del Reglamento de Cobertura, conforme aclaró la oficina requerida. Para determinar si la enfermedad realmente era de origen profesional, se realizó un diagnóstico por un especialista designado por la AFCC y otro diagnóstico complementario por otro médico. El especialista finalmente concluyó que la enfermedad efectivamente era un síndrome de desgaste profesional (burnout), vinculado estrechamente al acoso psicológico sufrido por la demandante durante sus años de servicio, concluyendo así que la solicitud de reconocimiento de enfermedad profesional debería ser aceptada.

A pesar del informe médico inicialmente favorable a las pretensiones de la autora, a instancias de la AFCC se declara que no existían razones médicas que justificaran la presentación extemporánea de la solicitud del reconocimiento. Así, la oficina de la Comisión requerida, en calidad de AFCC, el 1 de agosto de 2018 inadmitió la solicitud de reconocimiento del origen profesional de la enfermedad, por extemporánea, puesto que el art. 16 del Reglamento de cobertura exigía que dicha solicitud fuera presentada en un plazo razonable tras el inicio de la enfermedad, y en el caso de la demandante fue presentada tras casi 13 años del inicio de los síntomas. Además, la oficina de la Comisión alegó que la demandante podía haber solicitado en el mismo momento en que solicitó asistencia en el año 2013, el reconocimiento de la enfermedad profesional.

\section{Alegaciones de las partes}

La demandante alega no obstante, que AFCC con esta decisión le priva del derecho a ser oída, puesto que el médico designado por la institución que le diagnosticó nunca le hizo preguntas acerca de los motivos del retraso de la presentación de la solicitud de reconocimiento, no pudiendo así aclarar en ningún momento las razones de que presentase la declaración más tarde del inicio de su enfermedad. La AFCC por el contrario alega que aunque la decisión afecta desfavorablemente a la demandante, en este caso no hay obligación por parte de la institución a oír previamente a la interesada antes de adoptarla, reconociéndose tal derecho a ser oído solamente en procedimientos administrativos iniciados contra el interesado, no a instancias del interesado. La AFCC alega además que en dichos procedimientos iniciados por los interesados son los propios quienes deben aportar los datos necesarios para la estimación de la solicitud.

\section{Fundamentos de derecho de la sentencia del Tribunal General}

1. Vulneración del derecho de defensa e incumplimiento de la obligación de motivación

El fundamento de derecho segundo de la sentencia del Tribunal General analiza uno de los motivos de la demandante para fundamentar su pretensión de anulación de la decisión: la vulneración del derecho a ser oída y por consiguiente derecho a defenderse y la falta de motivación de la decisión de la Comisión.

La demandante invoca el derecho a ser oída, y alega que la decisión hubiera sido distinta si se le hubiese dado la oportunidad de explicar las razones de su extemporaneidad en la presentación de la solicitud del reconocimiento, porque el derecho a ser oído consiste precisamente en que el interesado pueda defenderse, expresando su perspectiva acerca de la situación. 
Conforme al art. 41 - que garantiza el derecho a una buena administración - en el apartado segundo, letra a) de la Carta de los Derechos Fundamentales de la Unión Europea, es un derecho de toda persona "ser oída antes de que se tome en contra suya una medida individual que le afecte desfavorablemente". Además, los artículos 47 y 48 de la Carta garantizan el respeto del derecho de defensa.

La demandante también alega que falta motivación, pues la respuesta del médico a la pregunta de si había algún motivo clínico para el retraso en la presentación de la solicitud del reconocimiento no fue en ningún momento confirmada o respaldada.

Respecto al derecho a ser oído, el Tribunal General aclara que desde el 1 de diciembre de 2009 la Carta es directamente vinculante a todos los Estados miembros, teniendo el mismo valor jurídico que los Tratados, siendo por tanto de aplicación general, por lo que el derecho a ser oído antes de adoptar una decisión administrativa conforme está contemplado en el art. 41, segundo apartado, letra a), es de aplicación general a toda persona siempre antes de que se tome contra ella una medida desfavorable. Al ser de aplicación general, su eficacia no depende de la naturaleza del procedimiento administrativo en específico, y al contrario de lo que defiende la Comisión, no es necesario estar ante un procedimiento iniciado contra el interesado para que sea de aplicación, debiendo respetarse también en procedimientos instados por los interesados. Conforme a la sentencia, la Comisión para defender la impertinencia de la alegación de la demandante respecto al derecho a ser oída, utiliza una doctrina y jurisprudencia desfasadas puesto que son anteriores a la entrada en vigor de la Carta, y por consiguiente son anteriores a un momento en que la Carta ya despliega eficacia general y directa del derecho a ser oído entre otros derechos que consagra.

\section{A. ¿Cualquier vulneración del derecho a ser oído puede significar la anulación de la decisión adoptada en el procedimiento administrativo?}

Los derechos fundamentales como el derecho de defensa, y su vertiente concreta del derecho a ser oído no son prerrogativas absolutas, por el contrario, son derechos susceptibles de menoscabo en el juego de la ponderación de derechos, porque siempre que existan objetivos de interés general que no signifiquen una vulneración desmesurada que afecte al núcleo duro del derecho fundamental, es decir, a su esencia, se podrá adaptar o limitar en beneficio del interés más necesitado de protección (sentencia de 10 de septiembre de 2013, G. y R., C 383/13 PPU, apartado 33).

Conforme reiterada jurisprudencia, una decisión que vulnere el derecho a ser oído solo es nula cuando el procedimiento de resolverse sin tal irregularidad hubiese tenido un resultado diferente. Esta es uno de los argumentos que utiliza la Comisión para defender en el presente caso la improcedencia de la nulidad de la decisión, puesto que los argumentos de la autora ya eran conocidos por el órgano de la Comisión con lo cual cualquier otro argumento deducido por la demandante al ser debidamente oída no habría cambiado la decisión.

No obstante, para el Tribunal General no se puede defender que la AFCC habría tomado la misma decisión si la demandante hubiese podido ejercer su derecho a ser oída, puesto que la realidad es que la autora no tenía siquiera conocimiento de la existencia de un dictamen realizado por el médico designado por la AFCC, ya que la misma no fue notificada ni del proyecto de decisión ni de las conclusiones de los médicos, como manda la 
Reglamentación de cobertura en el art. 20, apartado 1. Por todo ello, el Tribunal General determina la nulidad de la decisión impugnada.

\section{El ámbito de aplicación de la Carta de los Derechos Fundamentales de la Unión Europea}

Conviene antes que nada exponer algunas ideas sobre la real eficacia de la Carta de los Derechos Fundamentales de la Unión Europea. Conforme al art. 51 las disposiciones de la Carta "están dirigidas a las instituciones, órganos y organismos de la Unión, dentro del respeto del principio de subsidiariedad, así como a los estados miembros únicamente cuando apliquen el Derecho de la Unión". Este artículo delimita el ámbito de aplicación de la Carta de forma expresa a las propias competencias atribuidas a la Unión a través de los Tratados. Lo que la Carta trata de respetar mediante este artículo es el principio de atribución competencial, conforme al cual la Unión Europea solo tiene competencias atribuidas, siendo las competencias no atribuidas materia que está fuera del alcance de la Carta. Este delimitado campo de actuación representa un problema para la aplicación de la Carta, porque hay que determinar en cada caso y en cada relación jurídica con los Estados, cuando estos actúan desde la base jurídica de los tratados o desde la base jurídica de sus propias constituciones (Calahorro, 2018).

\section{El derecho a ser oído}

Conforme a reiterada jurisprudencia el derecho a ser oído implica un derecho del interesado en definir su postura, su punto de vista y su visión sobre las circunstancias, durante todo el procedimiento antes de que se adopte alguna decisión que le sea desfavorable (sentencia de 21 de noviembre de 1991, TV Munchen, C-269/90, y sentencia de 22 de noviembre de 2012, asunto C-277/11, apartado 87).

A pesar de que como ya se ha comentado los derechos fundamentales de la Carta pueden ser objeto de limitaciones, conforme a su art. 52 toda limitación de un derecho consagrado en la misma debe venir establecida por ley, respetando siempre el contenido esencial y el principio de proporcionalidad y cuando así lo requiera el interés general.

\section{Burnout: enfermedad reconocida como profesional por la OMS}

La Unión Europea no tiene potestad para determinar el listado de enfermedades profesionales de cada Estado miembro, no obstante sí que puede dictar meras Recomendaciones de carácter no vinculante. El burnout no obstante ya es reconocido por la Organización Mundial de la Salud (OMS) como una enfermedad profesional, que pasa a incluir esta patología en la Clasificación Internacional de Enfermedades que entrará en vigor en 2022. Es definida por la OMS como una síndrome resultante del estrés en el ámbito laboral, y que no debe ser aplicado para describir patologías experimentadas en otros ámbitos de la vida. Esta decisión de la OMS es un gran paso para implicar a los Estados miembros en la inclusión de esta enfermedad en su clasificación de enfermedades profesionales, aunque la única norma sanitaria vinculante de la OMS - y que a pesar de tal carácter no establece ningún tipo de sanción por su incumplimiento por parte de los Estados firmantes - es el Reglamento Sanitario Internacional del año 2007.

Definitivamente aun queda mucho recorrido en los Estados miembros para que un trastorno psicológico de incidencia cada vez más recurrente en la población sea incluido en el listado de enfermedades profesionales para así ofrecer un ámbito de mayor protección a los trabajadores. 


\section{Conclusiones}

Mediante la estimación del recurso analizado por parte del Tribunal General, se refuerza el carácter vinculante de la Carta de los Derechos Fundamentales de la Unión Europea, que a pesar de estar limitada al reparto de competencias realizado por los Tratados, en el ámbito interno de funcionamiento de la Unión - en sus instituciones y órganos - tiene plena eficacia. Así, una decisión que es tomada vulnerando el derecho a ser oído, tratándose de cualquier tipo de procedimiento administrativo - instado de oficio o por el propio administrado - , y siempre que provoque efectos desfavorables para el interesado, es susceptible de anulación cuando de haberse dado la decisión respetando dicho derecho de defensa no se hubiese tomado una decisión idéntica.

\section{REFERENCIAS BIBLIOGRÁFICAS}

- ¿Son jurídicamente vinculantes para España las Recomendaciones de la OMS relativas al COVID-19? (2020, marzo 16). Recuperado el 22 de julio de 2021, de Laleynext.es website: https://diariolaley.laleynext.es/dll/2020/03/23/son-juridicamente-vinculantes-paraespana-las-recomendaciones-de-la-oms-relativas-al-covid-19

- Aguilar Calahorro, A. (2018). La aplicación nacional de la Carta de Derechos Fundamentales de la UE: una simple herramienta de interpretación de la eficacia de las directivas. Revista de Derecho Comunitario Europeo, 61, 973-1011. doi: https://doi.org/10.18042/ cepc/rdce.61.05

- Burn-out an "occupational phenomenon": International Classification of Diseases. (n.d.). Recuperado de Who.int website: https://www.who.int/news/item/28-05-2019-burn-outan-occupational-phenomenon-international-classification-of-diseases

- Castillo de la Torre, F. y Nemeckova, P. (2020). Crónica de jurisprudencia del Tribunal de Justicia de la Unión Europea, mayo-agosto, 2020. Revista de Derecho Comunitario Europeo, 67, 1063-1133. doi: https://doi.org/10.18042/cepc/rdce.67.09

- El burnout, reconocido por la OMS como una enfermedad profesional. (2019, mayo 30). Recuperado el 22 de julio de 2021, de Prevencionar.com website: https://prevencionar. com/2019/05/30/el-burnout-reconocido-por-la-oms-como-una-enfermedad-profesional/ - Viñuales Ferreiro, S. (2015). El artículo 41 de la carta de los Derechos Fundamentales de la Unión Europea: una visión crítica. Estudios De Deusto, 63(1), 423-435. https://doi. org/10.18543/ed-63(1)-2015pp423-435 